\title{
The effects of cultural adaptation in fundraising letters: The case of help-self and help-others appeals in a feminine culture
}

\author{
JOS HORNIKX, BERNA HENDRIKS and DENISE THIJZEN \\ E-mails: j.hornikx@let.ru.nl; b.hendriks@let.ru.nl \\ dthijzen@gmail.com
}

\begin{abstract}
Gender has been shown to affect the persuasiveness of help-self and helpothers appeals in fundraising: men prefer help-self appeals, and women help-others appeals. This gender difference has been attributed to worldview differences. Women have a care-oriented world-view and men a justice-oriented world-view - at least in masculine cultures. In feminine cultures, however, both men and women have a care-oriented world-view. The present study investigated whether in the feminine, Dutch culture the culturally adapted help-others appeal was more persuasive than the culturally unadapted help-self appeal for both men and women $(N=166)$. Results showed that the culturally adapted help-others appeal was the most persuasive appeal for men and women, who were both found to have a relatively care-oriented world-view.
\end{abstract}

Keywords: Appeal, Fundraising, Gender, Masculinity-Femininity, Persuasion

\section{Introduction}

Donations from organizations and citizens are indispensable to charities that help people in need. Fortunately, a great many people are willing to donate to social causes, although surveys have revealed international variation in contributions as a result of differences in taxation systems. In Europe, total amounts of donations in 2005 varied from .14\% of GDP in France to $.45 \%$ in the Netherlands and $.73 \%$ in the UK (Charities Aid Foundation, 2006). In 2005, $97 \%$ of Dutch households reported they occasionally gave money to charitable organizations (Schuyt et al., 2007). Fundraising letters have been, and still are a popular instrument used to convince people to donate. In the Netherlands alone, over 17 million fundraising letters were sent out in 2003, raising approximately 40 million euros (Hoeken and Hustinx, 2007). 
If the number of potential donators is high, so is the number of charitable organizations. In the Netherlands, for instance, hundreds of charities, 268 of which were accredited in 2007, all vie for the attention of the Dutch (CBF, 2007). In such a highly competitive market, fundraisers increasingly face the need to design more effective fundraising letters to persuade their audience to donate money (see Bendapudi, Singh, and Bendapudi, 1996). A number of communication strategies have recently been studied in the context of fundraising, such as using exemplars (Hoeken and Hustinx, 2007), mentioning previous donations (Shang, Reed, and Croson, 2008), providing evidence (Das, Kerkhof, and Kuiper, 2008), and selecting an appropriate appeal (Brunel and Nelson, 2000). For fundraising appeals, experimental studies such as Brunel and Nelson $(2000,2003)$ have demonstrated that the persuasiveness of specific appeals depends on their congruence with readers' gender. That is, gender-adapted appeals (e.g., a help-self appeal such as "Save your life ... and protect your future" in the case of male readers) are more effective than gender-unadapted appeals (e. g., a help-others appeal such as "Save people's lives ... and help others live" in the case of male readers). In this paper, we argue that the persuasiveness of these two fundraising appeals - help-self and help-others appeals - may also depend on the cultural background of the audience, such that culturally adapted appeals (i.e., help-others in a feminine culture) are more effective than culturally unadapted appeals (i. e., help-self in a feminine culture). The purpose of the present study was therefore to investigate the persuasiveness of a help-others and a help-self fundraising letter in a feminine culture.

\section{Help-others and help-self appeals adapted to gendered values}

Fundraising letters are typically aimed at raising money for others in need, and as such often present their readers with altruistic reasons for helping. The goal of helping behaviour is thus to enhance the welfare of others. For some kinds of behaviour, such as organ donation (e. g., Morgan and Miller, 2002), these altruistic reasons are evident and, consequently, a message with a help-others appeal (or other-benefit appeal; Fisher, Vandenbosch, and Antia, 2008) stressing the benefits for others may be deemed appropriate. However, readers may also be guided by other than altruistic motives, such as when a cause is personally relevant (e. g., a reader who has experienced heart problems), or will become personally relevant in the future (e.g., environmental issues). Readers' donations may then be prompted by a wish to increase their own welfare, which may make a message with a help-self appeal (or self-benefit appeal; Fisher et al., 2008) more explicitly emphasizing the benefits for 
the readers (and their family and friends) more effective. Finally, the motivation to respond positively to fundraising letters may also be a combination of these altruistic and egoistic perspectives (see Bendapudi et al., 1996).

The effectiveness of help-self vis-à-vis help-others appeals can be addressed through the congruency between message appeal and reader values. Messages expressing personality traits, or values that are congruent with a reader's own personality and values are more likely to be effective than messages with incongruent values (e. g., Chang, 2002; Wan, 2008). A basic tenet in the field of persuasion is to adapt messages to receiver characteristics, such as level of sensation-seeking (Stephenson and Southwell, 2006), self-construal (Van Baaren and Ruivenkamp, 2007), or cultural values (Aaker and Schmitt, 2001). Given the abundant research evidence for gender differences in the preference for values relating to help-others appeals and to help-self appeals (e.g., Cross and Madson, 1997; Ford and Lowery, 1986; Gilligan, 1982; Guimond, 2008; Lyons, Duxbury, and Higgins, 2005), readers' gender appears to be an appropriate basis for adaptation. Men typically take on an instrumental, agentic role, which can be characterized as being self-focussed and task-oriented, and as emphasizing instrumental self-protection, self-assertion, isolation, and repression of emotion (Lyons et al., 2005). People with a male gender role generally value what is of concern to themselves. Women more typically fulfil an expressive, communal role, which can be characterized as expressive, open, and person-oriented. People with a communal role generally value what is of interest to or might be beneficial to themselves and others (Lyons et al., 2005). Gender differences in value preferences have also been referred to as a difference in world-view: men have a justice-oriented world-view, whereas women have a care-oriented worldview (Gilligan, 1982).

If men and women have different gender roles and world-views, they can be expected to respond differently to help-others appeals (congruent with women's world-view) and help-self appeals (congruent with men's world-view). Few studies, however, have compared the relative effectiveness of these two appeals for men and women. Hupfer (2006) investigated how Canadian men and women reacted to blood donor appeals in messages with either a communal (help-others) or an agentic (helpself) appeal. Two messages were created: one for a blood bag (which was less self-relevant to participants), and one about a road accident (which was highly self-relevant). For the blood bag message, the help-others appeal was the most persuasive, but for the road accident message, the help-self appeal was more persuasive. Whereas self-relevance of the message affected the responses to the two appeals, gender did not. Brunel and Nelson $(2000,2003)$ investigated a fundraising message about cancer 
research that was presented as self-relevant (through a help-self appeal) or as not self-relevant (through a help-others appeal) among American participants. In Brunel and Nelson (2000, Study 1) the male respondents favoured (and had a more positive attitude toward) the charitable message with the egoistic help-self appeal, whereas the female respondents favoured (and had a more positive attitude toward) the empathic helpothers appeal. Brunel and Nelson (2000, Study 2) also demonstrated that the gender differences could be fully attributed to participants' worldview (care-oriented or justice-oriented). Women proved to be more careoriented than men, who were more justice-oriented. These gender adaptation effects were corroborated in three follow-up studies (Brunel and Nelson, 2003, Study 2; Nelson et al., 2006, Study 1, Americans; Nelson et al., 2006, Study 2, Canadians), but not in Brunel and Nelson (2003, Study 1$)^{1}$. In sum, the research evidence to date does not indicate that one of the fundraising appeals systematically outperforms the other, but rather that their effectiveness may depend on the audience's gender. Appeals adapted to gendered values (e. g., help-others for women) are more effective than appeals that are negatively adapted to gendered values (e. g., help-self for women).

\section{Help-others and help-self appeals adapted to cultural values}

Although differences in gender roles have been attested by numerous scholars (for overviews, see Guimond, 2008; Lyons et al., 2005), these differences do not appear to be universal across different cultures. In fact, gender roles depend on the important values in a given culture (e. g., Wood, 1994; Rokeach, 1973). Research has amply demonstrated that although cultures share the same sets of values, they may differ with respect to which values are regarded as more important than others (Hofstede, 1980, 2001; House et al., 2004). One of the dimensions on the basis of which Hofstede $(1980,2001)$ described cultural value preferences is masculinity-femininity. In masculine cultures, there are clear gender roles. Men are generally regarded as competitive, assertive, and hard, and are seen as the primary breadwinners, whereas women are regarded as the primary caregivers and are commonly found in a home setting and to be concerned with the quality of life. Women are expected to take care of the children, husbands and other people (Hofstede, 1980, 2001). In studies reporting on gender-adaptation effects of help-self and helpothers appeals (e. g., Brunel and Nelson, 2000, 2003), participants were from masculine cultures (Canada and U.S.), where help-others appeals can be regarded as adapted to women, and help-self appeals as adapted to men. 
In feminine cultures, however, adaptation of appeals to gendered values does not appear relevant because in such cultures both women and men endorse feminine values (Hofstede, 1980, 2001). In feminine cultures, the help-others appeal is a culturally adapted value appeal, whereas the help-self appeal can be considered a culturally unadapted value appeal. Appealing to help-others is congruent with the prevalent feminine values endorsed by both men and women in a feminine culture. There is some empirical work on the effects of adapting value appeals to masculinity-femininity. In their meta-analytic review of cultural adaptation of value appeals in advertising, Hornikx and O'Keefe (2009) identified 13 (persuasion outcomes) or 14 (ad liking outcomes) comparisons of values appeals that were adapted or unadapted to masculinity-femininity. Adaptation effects were found for ad liking but not for persuasion. Ads with appeals that were adapted to the level of femininity-masculinity of participants' culture were better liked than ads with unadapted appeals.

In the context of fundraising, one study on cultural value adaptation on masculinity-femininity was identified. Nelson et al. (2006) investigated the effectiveness of the two fundraising messages from the Brunel and Nelson (2000) study for men and women in two masculine cultures and two feminine cultures. Contrary to expectations expressed above, women from the feminine, Danish culture (Study 1) and the feminine, Norwegian culture (Study 2) were more persuaded by the help-self appeal than by the help-others appeal. Nelson et al. (2006) suggest that overlapping gender roles in these highly feminine cultures make women relatively more masculine than men, but this does not seem consistent with Hofstede's $(1980,2001)$ empirical data relating to masculinity-femininity. The overlap between gender roles has indeed been claimed and demonstrated in feminine cultures, but in such a way that both men and women take on relatively feminine roles. Unfortunately, Nelson et al. (2006) did not measure participants' world-view or their masculinity, which would have enabled them to empirically test the overlapping gender roles in Denmark and Norway.

For a fundraising letter to be effective, it seems worthwhile to adapt the appeal to audience characteristics. In masculine cultures, adaptation to gender has proven to increase the persuasiveness of fundraising messages. In feminine cultures, it may be more fruitful to adapt to cultural values. Because both men and women in feminine cultures can be expected to have a care-oriented rather than a justice-oriented world-view, help-others appeals are expected to be more persuasive than help-self appeals. The main purpose of the present study was to compare the persuasiveness of a fundraising letter with a culturally adapted helpothers and a culturally unadapted help-self appeal in a feminine culture. 
The Netherlands was selected because it is the second most feminine culture after Norway (Hofstede, 1980, 2001).

H1: For Dutch men and women, a fundraising letter with a help-others appeal is more persuasive than one with a help-self appeal.

If a cultural audience adaptation effect were to be found, it might possibly be explained by participants' care-oriented world-view. The only other study in this domain (Nelson et al., 2006) did not measure worldview. As the assessment of relevant personal characteristics is an important tool in cultural research (Hoeken and Korzilius, 2003), a study was conducted which did include this measure.

\section{Method}

The present study used a research design in which participants from one culture judged a message with either a culturally adapted appeal or a culturally unadapted appeal. This design corresponds with a number of advertising studies on cultural adaptation (e. g., Agrawal and Maheswaran, 2005; Gregory and Munch, 1997).

\section{Material}

A one page fundraising letter was constructed, of which the fictitious sender was the Dutch Muscular Diseases Fund, a charity for the treatment of muscle diseases, such as Multiple Sclerosis, and Parkinson's Disease. As this charity deals with a variety of diseases, it is potentially relevant to a large number of citizens. Also, and more importantly, the letter could be framed as self-relevant through a help-self appeal or as not self-relevant through a help-others appeal. The letter included background information on the urgency of the cause, the aim of the letter, and a description of a person who successfully benefits from the charity. Two versions were constructed, one with a help-self appeal (a letter containing 297 words; see Appendix 1 for an English translation), and one with a help-others appeal (containing 289 words; see Appendix 2). Following the advice of Abelen, Redeker, and Thompson (1993), the headings of the two letters, which were manipulated to have either a helpself or a help-others tone (cf. Brunel and Nelson, 2000), were printed in a handwritten font. Important sentences in the letter were underlined to make the two appeals more salient (cf. Abelen et al., 1993). The letter asked readers to donate money needed for research into effective treatments "that patients need in the future" (help-others) or "that you will perhaps need in the future" (help-self). The letter concluded by saying 
that "there is no better way to protect the future of patients" (helpothers) or "to protect your own future and the future of your family" (help-self).

In a pre-test, 57 Dutch students $(52.6 \%$ female, age: $M=21.42, S D$ $=1.67$, range $18-27$ ) received one of the two fundraising letters. The pre-test was conducted to assess the recognition of the two appeals, the perceived efficacy of donating to the cause, and the typicality of the two letters. The pre-test was successful for all three measures. For appeal recognition, participants were asked to pick four values from a list of Schwartz (1994) values related to help-others (e.g., helping others) or to help-self (e.g., safety for family). The two different appeals were recognized by the participants. Those who read the help-others letter picked more help-others values $(M=0.64, S D=0.18)$ than those who read the help-self letter $(M=0.53, S D=0.21) ; t(55)=2.05, p<.05$; those who read the help-self letter picked more help-self values $(M=0.36, S D=$ $0.27)$ than those who read the help-others letter $(M=0.17, S D=0.20)$; $t(55)=2.98, p<.01$. People's reactions to fundraising letters may vary depending on the efficacy of the promise made in the letter (cf. Das et al., 2008). Perceived efficacy was measured on a 6-point Likert scale by asking participants to judge to what extent a donation would contribute to research which would favour the patients mentioned in the letter: patients in general (help-others) or future patients including the reader (help-self). For both versions of the letter, participants were convinced by the efficacy of the cause advocated by the letter as the efficacy ratings exceeded the midpoint of the 6-point scale (help-self: $M=4.94, S D=$ $1.25, t(32)=6.62, p<.001$; help-others: $M=5.04, S D=1.00, t(32)$ $=7.56, p<.001)$. Finally, both letters were considered to be typical fundraising letters as the typicality ratings exceeded the midpoint of the 6-point scale (help-self: $M=4.79, S D=1.08, t(32)=6.83, p<.001$; help-others: $M=5.04, S D=0.91, t(55)=8.32, p<.001)$.

\section{Participants}

A total of 166 Dutch respondents from various professional backgrounds, such as administrative staff, account managers, lecturers, product managers, IT consultants, and medical professions, took part in the experiment. There were 81 participants (53\% female) who read the helpself letter, and 85 participants (58\% female) who read the help-others letter. Most participants had finished higher education $(85 \%$ in the helpself group, $86 \%$ in the help-others group; $86 \%$ of the female participants, $85 \%$ of the male participants). Participants' ages varied between 20 and 66 in the help-self group $(M=37.49, S D=12.51)$, and between 
22 and 65 in the help-others group $(M=38.79, S D=12.88)$. The two groups did not differ in the percentage of female participants $\left(\chi^{2}(1)=\right.$ $0.35, p=.56)$ or in mean ages $(t(163)=0.65, p=.52)$.

\section{Instrumentation}

The persuasiveness of the fundraising letter was measured on the basis of donation intention, attitude towards donation, credibility of the organization, and attitude towards the letter.

Donation intention. Donation intention was measured using 6-point semantic differentials (very improbable-very probable) for the two questions "How likely are you to consider donating money to this charity after reading this letter?", and "How likely are you to actually donate money to this charity after reading this letter?" $(\alpha=.81)$.

Attitude towards donation. Attitude towards donation was measured by having participants complete the statement "Giving money to the Muscular Diseases Fund is" with the four 6-point semantic differentials irresponsible-responsible, bad-good, stupid-smart, and unworthy-worthy $(\alpha=.87)$.

Credibility of the organization. The organization's credibility was assessed through the statement "I find the organization" followed by four 6-point semantic differentials (extremely incredible-extremely credible, unprofessional-professional, dishonest-honest, selfish-unselfish; $a=.83$ ).

Attitude towards the letter. For the attitude towards the letter participants completed the statement "I find the letter" by answering five 6-point semantic differentials: monotonous-varied, elaborate-succinct, annoying-pleasant, boring-interesting, not nice read-nice to read $(\alpha=.89)$.

World-view. A Dutch version of the World-View Questionnaire (WVQ; Jensen, McGhie, and Jensen, 1991; Stander and Jensen, 1993) with its 40 pairs of care words (e. g., getting along with others) and justice words (e. g., achievement) was included. The WVQ was translated into Dutch and translated back into English. For each pair (e.g., helping-leadership), participants were asked to pick the word that appealed to them most. The care-oriented or justice-oriented world-view score was based on the number of care words chosen $(0=$ justice-oriented, $40=$ care-oriented).

Personal information. Finally, participants answered personal questions regarding their gender, age, nationality, mother tongue, highest level of education, and current job function. 


\section{Design and procedure}

The study had a 2 (appeal: help-self-help-others) $\times 2$ (gender: malefemale) between-subjects factorial design. A group of students was asked to assist us in recruiting working people to participate in the study. All students were randomly given a link to a website containing one of the two versions of the questionnaire, and were asked to forward this link to working acquaintances, who were invited to participate in the study. Participants first read a short introduction which was followed by one of the two fundraising letters, and were subsequently asked to answer the questions.

\section{Results}

The hypothesis (H1) about the effectiveness of help-self and help-others appeals to men and women in a feminine culture was evaluated using a 2 (appeal) $\times 2$ (gender) MANOVA. The scores for all four conditions on the dependent variables are given in Table 1. First, there was a main effect of appeal on persuasiveness $\left(F(4,159)=4.01, p<.01, \eta^{2}=.09\right)$ : the culturally adapted help-others appeal $(M=3.85, S D=0.69)$ was more persuasive than the culturally unadapted help-self appeal $(M=$ $3.55, S D=0.66)$. This main effect was found for two dependent measures: organization's credibility $\left(F(1,162)=5.06, p<.05, \eta^{2}=.03\right)$, and attitude towards the letter $\left(F(1,162)=13.86, p<.001, \eta^{2}=.08\right)$. The help-others appeal generated a higher credibility of the organization

Table 1. Persuasiveness in function of appeal and gender of participants.

\begin{tabular}{|c|c|c|c|c|c|c|c|c|c|}
\hline & \multicolumn{3}{|c|}{$\begin{array}{l}\text { Donation } \\
\text { Intention }\end{array}$} & \multicolumn{2}{|c|}{$\begin{array}{l}\text { Attitude } \\
\text { Towards } \\
\text { Donation }\end{array}$} & \multicolumn{2}{|c|}{$\begin{array}{l}\text { Credibility of } \\
\text { Organization }\end{array}$} & \multicolumn{2}{|c|}{$\begin{array}{l}\text { Attitude } \\
\text { Towards } \\
\text { The Letter }\end{array}$} \\
\hline & $M$ & $S D$ & $n$ & $M$ & $S D$ & $M$ & $S D$ & $M$ & $S D$ \\
\hline \multicolumn{10}{|c|}{ Help-Others } \\
\hline Male & 2.72 & 1.09 & 36 & 4.17 & 0.67 & 4.10 & 0.80 & 3.59 & 0.74 \\
\hline Female & 3.08 & 1.15 & 49 & 4.56 & 0.67 & 4.44 & 0.80 & 3.93 & 0.91 \\
\hline Total & 2.92 & 1.13 & 85 & 4.39 & 0.69 & $4.30^{*}$ & 0.81 & $3.79 * * *$ & 0.85 \\
\hline \multicolumn{10}{|l|}{ Help-Self } \\
\hline Male & 2.57 & 1.13 & 38 & 4.20 & 0.79 & 3.92 & 0.96 & 3.30 & 0.94 \\
\hline Female & 2.74 & 0.96 & 43 & 4.38 & 0.69 & 4.05 & 0.71 & 3.22 & 0.84 \\
\hline Total & 2.66 & 1.04 & 81 & 4.29 & 0.74 & 3.99 & 0.83 & 3.26 & 0.88 \\
\hline
\end{tabular}

Note: $* p<.05, * * * p<.001$, differences between appeals. The $n \mathrm{~s}$ given for donation intention apply to all dependent variables in a given row. 
$(M=4.30, S D=0.81)$ than the help-self appeal $(M=3.99, S D=0.83)$, and a more positive attitude towards the letter $(M=3.79, S D=0.85)$ than the help-self appeal $(M=3.26, S D=0.88)$. There was no main effect of gender on the persuasiveness of the fundraising letter $(F(4,159)$ $=1.90, p=.11)^{2}$. The hypothesis was further addressed through the assessment of an interaction between appeal and gender. This interaction effect on persuasion was not significant $(F(4,159)<1)$. This means that, as expected, the main effect of appeal was not qualified by the gender of the participants.

\section{World-view}

The absence of an interaction effect between gender and appeal was expected for the Dutch participants because of the care-oriented worldview in the feminine culture. Therefore, we first checked the scores of the participants on world-view. Female participants had a care-oriented world-view rather than a justice-oriented world-view $\left(M_{\text {care words }}=24.53\right.$, $S D=5.36 ; t(91)=8.11, p<.001)$, and the same applied to the male participants $\left(M_{\text {care words }}=21.45, S D=6.38 ; t(73)=1.95, p=.06\right)$. The female participants were found to have a more pronounced care-oriented world-view than the male participants $\left(F(1,164)=11.47, p<.01, \eta^{2}\right.$ $=.07)$.

Next, it was investigated whether world-view was directly related to the persuasiveness of the adapted help-others and the unadapted helpself appeals. After dichotomizing the scores on the WVQ (justice-oriented vs care-oriented), a MANOVA was conducted with world-view and appeal as factors. For world-view to be an explanation for the adaptation effect, the interaction between world-view and appeal should have been significant, which it was not: $F(4,159)<1$.

\section{Conclusion and discussion}

In an attempt to convince people to donate money, charity fundraisers design letters to promote their causes. In most of these letters, the benefits of donating can be described as enhancing the welfare of others (help-others appeal) or the readers (help-self appeal). Previous studies have demonstrated that the effectiveness of these appeals may depend on the gender of recipients (e. g., Brunel and Nelson, 2000, 2003), at least in masculine cultures: men tend to prefer help-self appeals, and women help-others appeals. This relationship between gender and appeal type can be explained by the congruency between the message appeal and the values that are endorsed by males and females. That is, the help-self appeal is adapted to men, who have a justice-orientation, and the help- 
others appeal is adapted to women, who have a care-orientation (cf. Gilligan, 1982; Guimond, 2008; Lyons et al., 2005).

It was argued that this adaptation effect is appropriate for masculine cultures, which have distinct gender roles (care-orientation vs justiceorientation), but inappropriate for feminine cultures (which are characterized by a care-orientation). For feminine cultures, it was expected that - for both men and women - the help-others appeal would be culturally adapted, and that the help-self appeal would be culturally unadapted. In this study, male and female potential donators from the feminine, Dutch culture judged a realistic fundraising letter, which contained either a help-others or a help-self appeal. The results show that the help-others appeal was more persuasive than the help-self appeal, and that this effect was not qualified by the gender of the participants. The help-others appeal generated a higher credibility of the organization, and a more positive attitude towards the letter, regardless of the gender of the participants. Although this finding supports the general notion of audience adaptation (cf. Chang, 2002; Wan, 2008; Hornikx and O'Keefe, 2009), it should be noted that differences between the culturally adapted and culturally unadapted appeals were not significant for two important outcomes, namely the attitude towards donation, and donation intention. That is, men and women responded more favourably to the culturally adapted appeal, but only on two dependent variables that are, arguably, less directly related to donating than the other two variables. The significant effects found for attitude towards the letter and credibility of the organization, however, were rather large: $r=.17$ for credibility of the organization, and $r=.28$ for attitude towards the letter. These effect sizes are larger than the average effect size found in the meta-analysis of Hornikx and O'Keefe (2009) that summarizes empirical investigations on cultural value adaptation in advertisements.

In order to put forward a cultural explanation for the adaptation effect, it is important to relate the personal characteristics of the participants to the dependent variables of interest. As the interaction between world-view and appeal on persuasiveness was not significant, the adaptation effect cannot be empirically attributed to world-view (i. e., the difference in persuasiveness between the help-others and the help-self appeal was not stronger for participants with a strong care-orientation than for participants with a weaker care-orientation). It should be noted that a lack of a direct empirical explanation such as in the present study has been reported frequently in studies on cultural adaptation of value appeals (see Hornikx and O'Keefe, 2009). To what extent can the cultural adaptation effect found in the present study be explained by culture? We address this question by discussing the measurement of personal characteristics, and by reviewing alternative explanations. 
A prerequisite for any cultural explanation to be put forward in cultural studies is to assess relevant personal characteristics (cf. Hoeken and Korzilius, 2003). The Nelson et al. (2006) study on help-others and helpself appeals did not assess such characteristics, but the present study did so by including the world-view questionnaire. Although women expressed a more pronounced care-orientation than men, both men and women were found to have a care-oriented world-view, which is consistent with the characteristics of members of feminine cultures (Hofstede, 1980, 2001).

Although the cultural adaptation effect cannot be empirically attributed to world-view, it can be interpreted by it. In the present study, the interpretation would centre upon the (in)congruence between care values endorsed in the Dutch culture on the one hand, and the value appeals in the letters on the other. A similar interpretation is also given, for instance, in Chang's (2006) study on femininity-masculinity appeals in advertising. Chang, who did not measure world-view but femininity, puts forward that "There is a strong case for arguing that differences [in the persuasiveness of the appeals] [...] are dependent upon differences in cultural masculinity/femininity" (p. 322).

Second, this cultural interpretation of the results is stronger to the extent to which alternative explanations can be ruled out. One alternative explanation might be that the culturally adapted help-others appeal was the more persuasive of the two because it is a more natural appeal for fundraising. This explanation does not seem to hold. Participants in the pre-test were convinced by the efficacy of the cause advocated by both appeals, and considered both letters to be typical fundraising letters. In conclusion, although the cultural adaptation effect found in the present study cannot be empirically attributed to participants' worldview, their scores on world-view do allow for a meaningful cultural interpretation of the results.

\section{Theoretical implications and future research}

The present study adds to the body of literature on the effectiveness of help-self and help-others appeals in fundraising letters in that it is the first study of its kind in a feminine culture to have taken into account participants' world-view. In a broader perspective, this study is also relevant for research on adapting persuasive messages to culture (e.g., Aaker and Schmitt, 2001; Han and Shavitt, 1994), gender (e. g., Andsager, Austin, and Pinkleton, 2002; Chang, 2006), and to culture and gender (e. g., Wang et al., 2000). This study underscores the different bases for adaptation (i.e., gender and culture) that need to be considered when aiming for effective persuasion. As one of the first studies on value adap- 
tation to masculinity-femininity outside of the advertising field, it highlights the need for more research on this cultural dimension (cf. Chang, 2006). Findings in the present study are limited to one specific fundraising letter, but the more the body of research accumulates, the more it will become clearer how culture and gender may affect persuasive outcomes. This study indirectly points to a complexity in adapting messages to culture and to gender. When adapting to cultural values in a feminine culture, the adapted, feminine value appeal is expected to be more persuasive than the unadapted, masculine value appeal regardless of the gender of the audience. When adapting to cultural values in a masculine culture, however, studies have generally compared the supposedly adapted, masculine appeal with the supposedly unadapted feminine appeal - again, regardless of the gender of the audience (e. g., Hoeken et al., 2007). We have put forward that in masculine cultures, the question of what is culturally adapted and what is not culturally adapted depends on the gender of the individual recipient: for male recipients, the masculine appeal is adapted, whereas for the female recipients, the feminine appeal is adapted. For future research on cultural adaptation to masculinity-femininity, we therefore urge that the gender of participants also be considered when analyzing the effects of cultural adaptation, as was the case in Wang et al. (2000). Paying attention to both the cultural characteristics and the gender of the audience may increase the effectiveness of value appeals in messages in fundraising and advertising.

Future research on cultural adaptation of help-self and help-others appeals in fundraising would benefit from including a personal characteristic other than world-view, namely femininity: the degree to which participants endorse feminine values more than masculine values. In the present study, scores on world-view could not explain the cultural adaptation effect that was found. By measuring both participants' world-view and femininity, a future study has a higher chance of attributing the cultural adaptation effect to personal characteristics. In addition, the present study focussed on the effectiveness of value adaptation within one specific culture. However, it may also be worthwhile to investigate the effectiveness of both appeals between a feminine culture and a masculine culture. If the help-others appeal is (again) more persuasive than the help-self appeal in the feminine culture, and if the help-self appeal is more persuasive than the help-others appeal in the masculine culture, there is more evidence to relate this cross-cultural difference to the level of femininity in both cultures. Of course, a future study with a femininity measure and with a second culture may potentially be in the best position to explain the possible cultural adaptation effect. 


\section{Practical implications}

For the specific fundraising letter used in the present study, the culturally adapted help-others appeal was found to be more effective than the culturally unadapted help-self appeal. If future studies were to corroborate this result, this would imply that in feminine cultures a fundraising letter with a help-others appeal should be favoured. Since this adaptation effect is independent of the gender of the audience, the letter does not need to be adapted. As such, the adaptation of a fundraising letter to masculinity-femininity in a feminine culture can even be regarded as relatively cost-effective. Other contributions to adapting persuasive messages have addressed the cost-effectiveness of adaptation (see, e.g., Rimer and Kreuter, 2006), which seems highly relevant in masculine cultures, where two letters would need to be designed: one that is supposed to be adapted to men, and one that is supposed to be adapted to women.

Although adaptation to cultural values may be fruitful, it is just one of several strategies that can be used to optimize the effectiveness of fundraising. An important question would be whether strategies that have been proven to work in isolation, such as framing (Das et al., 2008) or exemplars (Hoeken and Hustinx, 2007), will lead to even more effective fundraising letters when they are combined. Given the important causes of charity organizations, addressing such a question might help these charities to more effectively raise money to help other people, or to help you and your family.

\section{Notes}

1. In Brunel and Nelson (2003, Study 1), participants received two identical fundraising letters with a different appeal (help-self or a help-others), and indicated which of the two they found most persuasive. Letters were presented in two different orders: help-self first, or help-others first. Results showed that message order rather than match between gender and appeal determined participants' preferences: women preferred the first letter they read (primacy effect), and men the second letter (recency effect).

2. Statistical power to detect a main effect for gender was approximately .99 for a large effect size $(f=.40), .95$ for a medium effect size $(f=.25)$, and .28 for a small effect size $(f=.10$; Cohen, 1988).

\section{References}

Aaker, J. L. \& Schmitt, B. (2001). Culture-dependent assimilation and differentiation of the self: Preferences for consumption symbols in the United States and China. Journal of Cross-Cultural Psychology, 32(5), 561-576.

Abelen, E., Redeker, G., \& Thompson, S. A. (1993). The rhetorical structure of USAmerican and Dutch fund-raising letters. Text, 13(3), 323-350. 
Agrawal, N. \& Maheswaran, D. (2005). The effects of self-construal and commitment on persuasion. Journal of Consumer Research, 31(4), 841-849.

Andsager, J. L., Austin, E. W., \& Pinkleton, B. E. (2002). Gender as a variable in interpretationof alcohol-related messages. Communication Research, 29(3), 246269.

Bendapudi, N., Singh, S. N., \& Bendapudi, V. (1996). Enhancing helping behavior: An integrative framework for promotion planning. Journal of Marketing, 60(3), $33-49$.

Brunel, F. F. \& Nelson, M. R. (2000). Explaining gendered responses to "help-self" and "help-others" charity ad appeals: The mediating role of world-views. Journal of Advertising, 29(3), 15-28.

Brunel, F. F. \& Nelson, M. R. (2003). Message order effects and gender differences in advertising persuasion. Journal of Advertising Research, 43(3), 330-341.

CBF (2007). Jaarverslag 2007 [Annual report 2007]. Retrieved July 6, 2009, from http://www.cbf.nl/Downloads/Bestanden/Algemeen/jaarverslag_2007.pdf

Charities Aid Foundation (2006). International comparisons of charitable giving: November 2006. Retrieved July 6, 2009, from http://www.cafonline.org/pdf/Inter national $\% 20 \% 20$ Giving $\% 20$ highlights.pdf

Chang, C. (2002). Self-congruency as a cue in different advertising-processing contexts. Communication Research, 29(5), 503-536.

Chang, C. (2006). Cultural masculinity/femininity influences on advertising appeals. Journal of Advertising Research, 46(3), 315-323.

Cohen, J. (1988). Statistical power analysis for the behavioral sciences ( $2^{\text {nd }}$ ed.). Hillsdale, NJ: Lawrence Erlbaum.

Cross, S. E. \& Madson, L. (1997). Models of the self: Self-construals and gender. Psychological Bulletin, 122(1), 5-37.

Das, E., Kerkhof, P., \& Kuiper, J. (2008). Improving the effectiveness of fundraising messages: The impact of charity goal attainment, message framing, and evidence on persuasion. Journal of Applied Communication Research, 36(2), 161-175.

Fisher, R. J., Vandenbosch, M., \& Antia, K. D. (2008). An empathy-helping perspective on consumers' responses to fund-raising appeals. Journal of Consumer Research, 35(3), 519-531.

Ford, M. R. \& Lowery, C. R. (1986). Gender differences in moral reasoning: A comparison of the use of justice and care orientations. Journal of Personality and Social Psychology, 50(4), 777-783.

Gilligan, C. (1982). In a different voice: Psychological theory and women's development. Cambridge, MA: Harvard University Press.

Gregory, G. D. \& Munch, J. M. (1997). Cultural values in international advertising: An examination of familial norms and roles in Mexico. Psychology and Marketing, 14(2), 99-119.

Guimond, S. (2008). Psychological similarities and differences between women and men across cultures. Social and Personality Psychology Compass, 2(1), 494-510.

Han, S.-P. \& Shavitt, S. (1994). Persuasion and culture: Advertising appeals in individualistic and collectivistic societies. Journal of Experimental Social Psychology, 30(4), 326-350.

Hoeken, H. \& Hustinx, L. (2007). The impact of exemplars on responsibility stereotypes in fund-raising letters. Communication Research, 34(6), 596-617.

Hoeken, H. \& Korzilius, H. (2003). Conducting experiments on cultural aspects of document design: Why and how? Communications, The European Journal of Communication Research, 28(3), 285-304.

Hoeken, H., Starren, M., Nickerson, C., Crijns, R., \& van den Brandt, C. (2007). Is it necessary to adapt advertising appeals for national audiences in Western Europe? Journal of Marketing Communications, 13(1), 19-38. 
Hofstede, G. (1980). Culture's consequences: International differences in work-related values. Beverly Hills, CA: Sage.

Hofstede, G. (2001). Culture's consequences: Comparing values, behaviors, institutions, and organizations across nations $\left(2^{\text {nd }}\right.$ ed.). Thousand Oaks, CA: Sage.

Hornikx, J. and O'Keefe, D. J. (2009). Adapting consumer advertising appeals to cultural values: A meta-analytic review of effects on persuasiveness and ad liking. Communication Yearbook, 33, 38-71.

House, R. J., Hanges, P. J., Javidan, M., Dorfman, P. W., \& Gupta, V. (Eds.). (2004). Culture, leadership, and organizations: The GLOBE study of 62 societies. Thousand Oaks, CA: Sage.

Hupfer, M. E. (2006). Helping me, helping you: Self-referencing and gender roles in donor advertising. Transfusion, 46, 996-1005.

Jensen, L. C., McGhie, A. P., \& Jensen, J. R. (1991). Do men's and women's worldviews differ? Psychological Reports, 68, 312-314.

Lyons, S., Duxbury, L., \& Higgins, C. (2005). Are gender differences in basic human values a generational phenomenon? Sex Roles, 53(9/10), 763-779.

Morgan, S. E. \& Miller, J. K. (2002). Communicating about gifts of life: The effect of knowledge, attitudes, and altruism on behavior and behavioral intentions regarding organ donation. Journal of Applied Communication Research, 30(2), 163-178.

Nelson, R. M., Brunel, F. F., Supphellen, M., \& Manchanda, R. V. (2006). Effects of culture, gender, and moral obligations on responses to charity advertising across masculine and feminine cultures. Journal of Consumer Psychology, 16(1), 45-56.

Rimer, B. K. \& Kreuter, M. W. (2006). Advancing tailored health communication: A persuasion and message effects perspective. Journal of Communication, 56, s184-s201.

Rokeach, M. (1973). The nature of human values. New York: The Free Press.

Schuyt, T. N. M., Gouwenberg, B., Bekkers, R., Meijer, M.-M., \& Wiepking, P. (Eds.). (2007). Geven in Nederland 2007: Giften, legaten, sponsoring en vrijwilligerswerk [Giving in the Netherlands 2007: Gifts, legacies, sponsoring, and volunteering]. Den Haag: Elsevier.

Schwartz, S. H. (1994). Are there universal aspects in the structure and contents of human values? Journal of Social Issues, 50(4), 19-45.

Shang, J., Reed, A. II, \& Croson, R. (2008). Identity congruency effects on donations. Journal of Marketing Research, 45(3), 351-361.

Stander, V. \& Jensen, L. (1993). The relationship of value orientation to moral cognition: Gender and cultural differences in the United States and China explored. Journal of Cross-Cultural Psychology, 24(1), 42-52.

Stephenson, M. T. \& Southwell, B. G. (2006). Sensation seeking, the activation model, and mass media health campaigns: Current findings and future directions for cancer communication. Journal of Communication, 56, s38-s56.

Van Baaren, R. \& Ruivenkamp, M. (2007). Self-construal and values expressed in advertising. Social Influence, 2(2), 136-144.

Wan, H.-H. (2008). Resonance as a mediating factor accounting for the message effect in tailored communication - examining crisis communication in a tourism context. Journal of Communication, 58(3), $472-489$.

Wang, C. L., Bristol, T., Mowen, J. C., \& Chakraborty, G. (2000). Alternative modes of self-construal: Dimensions of connectedness-separateness and advertising appeals to the cultural and gender-specific self. Journal of Consumer Psychology, $9(2), 10-115$.

Wood, J. T. (1994). Gendered lives: Communication, gender, and culture. Belmont, CA: Wadsworth. 


\section{Appendix 1}

\section{Help-self letter (translated from Dutch)}

As a successful person, you value the importance of your health and the health of your family. Help us therefore in the search for causes and treatments of muscular disorders and protect your own future.

The Hague, November 2006

Dear Sir, Madam,

The Muscular Diseases Fund has, for some time now, dedicated itself to over 200,000 people in the Netherlands suffering from diseases that affect the muscles, such as Duchenne, Parkinson, MS, Polio and spasticity. You, too, can help us in this, as our efforts are only possible with the support of people like you.

Meet Maryze Schoneveld van der Linde from Varsseveld. When she was eight years old, she was diagnosed with the rare Pompe disease. This disease is characterized by a progressive weakening of the muscles and difficulties in breathing, which makes a wheelchair and a respirator indispensable. The Muscular Diseases Fund supports the research into the workings of a new cure for Pompe disease. The first test results are promising.

The Muscular Diseases Fund looks, with the support of donators, for causes and treatments of muscular disorders that you or your family might perhaps need in the future. We do this by closely working together with scientific staff and patient organizations, but also with patients and their families. In addition, to improve the quality of life, we provide holiday homes across the country to patients and their families.

By giving money to the Muscular Diseases Fund, you contribute to the search for causes and for treatments that you will perhaps need in the future. There is no better way to protect your own future and the future of your family. So, please help us in our struggle against muscular diseases.

Thank you in advance.

Yours faithfully,

Jan Dijkstra

Chairman Muscular Diseases Fund 


\section{Appendix 2}

Help-others letter (translated from Dutch)

As a caring person, you value the importance of helping others. Help us therefore in the search for causes and treatments of muscular disorders and help patients in need.

The Hague, November 2006

Dear Sir, Madam,

The Muscular Diseases Fund has, for some time now, dedicated itself to over 200,000 people in the Netherlands suffering from diseases that affect the muscles, such as Duchenne, Parkinson, MS, Polio and spasticity. You, too, can help us in this, as our efforts are only possible with the support of people like you.

Meet Maryze Schoneveld van der Linde from Varsseveld. When she was eight years old, she was diagnosed with the rare Pompe disease. This disease is characterized by a progressive weakening of the muscles and difficulties in breathing, which makes a wheelchair and a respirator indispensable. The Muscular Diseases Fund supports the research into the workings of a new cure for Pompe disease. The first test results are promising.

The Muscular Diseases Fund looks, with the support of donators, for the causes of muscular disorders and treatments that patients need. We do this by closely working together with scientific staff and patient organizations, but also with patients and their families. In addition, to improve the quality of life, we provide holiday homes across the country to patients and their families.

By giving money to the Muscular Diseases Fund, you contribute to the search for causes and treatments that patients need in the future. There is no better way to protect the future of patients. So, please help us in our struggle against muscular diseases.

Thank you in advance.

Yours faithfully,

Jan Dijkstra

Chairman Muscular Diseases Fund 